\title{
Maximum equivalent stress induced and the displacement of the developing permanent first molars after the premature loss of primary second molars: A finite element analysis
}

\author{
Arghavan Kamali Sabeti ${ }^{A, C, E}$, Zahra Karimizadeh ${ }^{A, B, D, F}$, Rezvan Rafatjou ${ }^{A, C}$ \\ Department of Pediatric Dentistry, Dental School, Hamadan University of Medical Sciences, Iran \\ A - research concept and design; $\mathrm{B}$ - collection and/or assembly of data; $\mathrm{C}$ - data analysis and interpretation; \\ $D$ - writing the article; $E$ - critical revision of the article; $F$ - final approval of the article
}

Address for correspondence
Zahra Karimizadeh

E-mail:Zahra_kmz69@yahoo.com

Funding sources

None declared

Conflict of interest

None declared

Received on January 13,2020

Reviewed on April 1, 2020

Accepted on May 5, 2020

Published online on December 31, 2020

Cite as

Kamali Sabeti A, Karimizadeh Z, Rafatjou R. Maximum equivalent stress induced and the displacement of the developing permanent first molars after the premature loss of primary second molars: A finite element analysis. Dent Med Probl. 2020;57(4):401-409. doi:10.17219/dmp/122041

DOI

$10.17219 / \mathrm{dmp} / 122041$

Copyright

○) 2020 by Wroclaw Medical University

This is an article distributed under the terms of the

Creative Commons Attribution 3.0 Unported License (CC BY 3.0)

(https://creativecommons.org/licenses/by/3.0/).

\begin{abstract}
Background. The use of a space maintainer during the deciduous dentition period at a proper time can prevent the consequences of the loss of the arch length in the future. There is controversy over the use of space maintainers.

Objectives. The aim of this study was to evaluate the magnitude of stresses exerted on immature permanent molar teeth, and the extent of displacement of these teeth when the adjacent teeth are missing, but after placing a space maintainer. Studies carried out to date have used clinical measurements, e.g., X-rays and dental casts.

Material and methods. The finite element model (FEM) was used for modeling the maxillary and mandibular teeth and the bone structure. A space maintainer (band and loop) was also designed for modeling. Force was applied and a finite element analysis (FEA) was carried out in 6 states in the maxilla and in the mandible to evaluate the distribution of stresses and the amount of displacement of immature permanent first molar teeth in the presence or absence of deciduous second molar teeth and a space maintainer.

Results. During mastication, when the deciduous second molar tooth was absent, the maximum stress was transferred to incomplete roots. When there was a space maintainer, stress was transferred to the space maintainer itself and to the distal side of the deciduous first molar tooth. The displacement of permanent first molar teeth was minimal in the presence of all teeth; in the absence of the deciduous second molar tooth, this displacement increased 4-5-fold, which decreased again almost to the level of the $1^{\text {st }} / 4^{\text {th }}$ state (intact arch) in the presence of the space maintainer.

Conclusions. The results showed the importance of the use of space maintainers, as they significantly decrease the momentary displacement of the teeth as well as the stress exerted on the developing permanent first molar teeth.
\end{abstract}

Key words: finite element analysis, space maintenance, mesial tooth movement 


\section{Introduction}

Space management is a crucial issue in pediatric dentistry. ${ }^{1}$ Local or systemic factors can lead to the early loss of deciduous teeth, including tooth extractions due to caries, traumatic injuries, and premature exfoliation resulting from abnormal root resorption and systemic disorders. Space reduction after the premature loss of primary second molars is one of the important factors affecting the occurrence of malocclusion, often increasing a demand for orthodontic treatment. ${ }^{2}$ The premature loss of deciduous second molars has the most significant effect on the dental arch, and the maximum space loss is due to the mesial drift of permanent first molar teeth. ${ }^{3}$ The use of a space maintainer during the deciduous dentition period at a proper time can prevent the consequences of the loss of the arch length in the future. ${ }^{4}$ It has been reported that the space change after the premature loss of a primary second molar in 3 weeks is statistically significant. ${ }^{5}$ A primary second molar is an eruption guide for a permanent first molar, so with the early loss of this guidance, a severe space loss will occur. The fastest and the greatest space closure occurs in the maxilla, followed by the mandible. ${ }^{6}$

There is controversy over the use of space maintainers. Some researchers believe that space maintainers are not useful and have detrimental effects in $19 \%$ of cases. ${ }^{7}$ There are a number of ill effects of conventional band and loop space maintainers - they lead to plaque retention, which causes gingivitis, the blanching of the gingivae due to band displacement, mucosal overgrowth, and loop impingement on the mucosa, causing pain and ulceration. ${ }^{8}$ Bilateral space maintainers may have questionable efficacy, and in case of the loss of multiple molars in the same quadrant, their use should be weighed against the risk of unwanted tooth movements, the loss of a removable space maintainer or no space maintenance at all. ${ }^{4}$

Space maintainers are mostly prescribed at a young age; their use is associated with some problems as a result of the patients' poor compliance, the possible manipulation of these appliances, and even the risk of swallowing a separated segment of the wires used as well as with economic problems. Therefore, in some cases, parents are not interested in the use of such appliances. ${ }^{9}$

The masticatory force is defined as a force that is created through the dynamic action of the masticatory muscles during the act of chewing. ${ }^{10}$ The force of mastication depends on many factors, including age, gender, tooth developmental stage, and hardness of food. This force is maximum in the molar area. The alveolar bone is immature and more elastic in children, less calcified, and has fewer trabeculae and larger bone marrow spaces as compared to adults. In addition, the lamina dura is thinner and the interdental crest is flatter than in the case of adults. ${ }^{11}$ In the mixed dentition period, permanent first molar teeth in the maxilla and the mandible are still developing and erupting; the roots of these teeth are not completely mature, making them very different from mature teeth. When a tooth is subjected to the physiologic force of mastication, stresses are transferred to the underlying bone through the periodontal ligament (PDL). Mature teeth with their long roots provide a large area to transfer these stresses and they are distributed on all root surfaces. However, in teeth that are still developing, only a small surface area of the root is available for transferring similar forces to the underlying bone. Therefore, it is expected that higher stresses will be induced in PDL. ${ }^{12}$ The analysis of the biomechanical properties of the tooth can help us understand the pattern of functioning of the periodontal tissue during mastication, and in general, the masticatory function. Therefore, it is necessary to construct a model to unify the structural geometry of the teeth, the tissue characteristics and the forces applied to the jaws. It is now well established that a model accurately simulating all the above variables is able to provide very accurate results. ${ }^{13}$ Currently, the need for a model such as the finite element model (FEM) has attracted attention. So far, no study has evaluated the magnitude of stresses exerted on immature permanent molar teeth with short roots and open apices, and the extent of displacement of these teeth when the adjacent teeth are missing; in addition, this displacement has not been evaluated after placing a space maintainer. Studies carried out to date have used clinical measurements, and none of them have made accurate evaluations with the use of a finite element analysis (FEA). Furthermore, studies using FEA have been very limited, especially in children during the mixed dentition period on immature molars. The stresses considered normal for mature teeth might be different for an immature, developing tooth; in addition, there are differences between maxillary and mandibular first molars in terms of the extent of displacement and bodily movement of the teeth.

The aim of this study was to evaluate the magnitude of stresses exerted on immature permanent molar teeth, and the extent of displacement of these teeth when the adjacent teeth are missing after a space maintainer was placed. Studies carried out to date have used clinical measurements, such as X-rays and plaster models (dental casts).

\section{Material and methods}

A finite element analysis was designed and applied in the present study to evaluate stresses and the displacement of maxillary and mandibular first molars in the mixed dentition period under normal masticatory forces in the presence or absence of deciduous second molar teeth and a space maintainer. To this end and to carry out the study on both jaws, three-dimensional (3D) models of the teeth, the jaws and a band and loop space maintainer were constructed as follows. 


\section{Preparation of a 3D model of the teeth}

A 3D model was designed using the cone-beam computed tomography (CBCT) images of a 6-year-old child whose permanent first molar teeth had erupted recently and established in the occlusal relationship (Fig. 1).

The model was designed accurately in its geometric dimensions, and deciduous first and second molars as well as permanent first molars were included in the model. The CBCT images were entered into a computer for processing 3D images, which converts $\mathrm{CBCT}$ and magnetic resonance imaging (MRI) data to $3 \mathrm{D}$ computer-aided design (CAD) models, and then the teeth were constructed. All tooth surface curves were recorded during the designing process, which resulted in an improvement in the accuracy of calculations in this model.
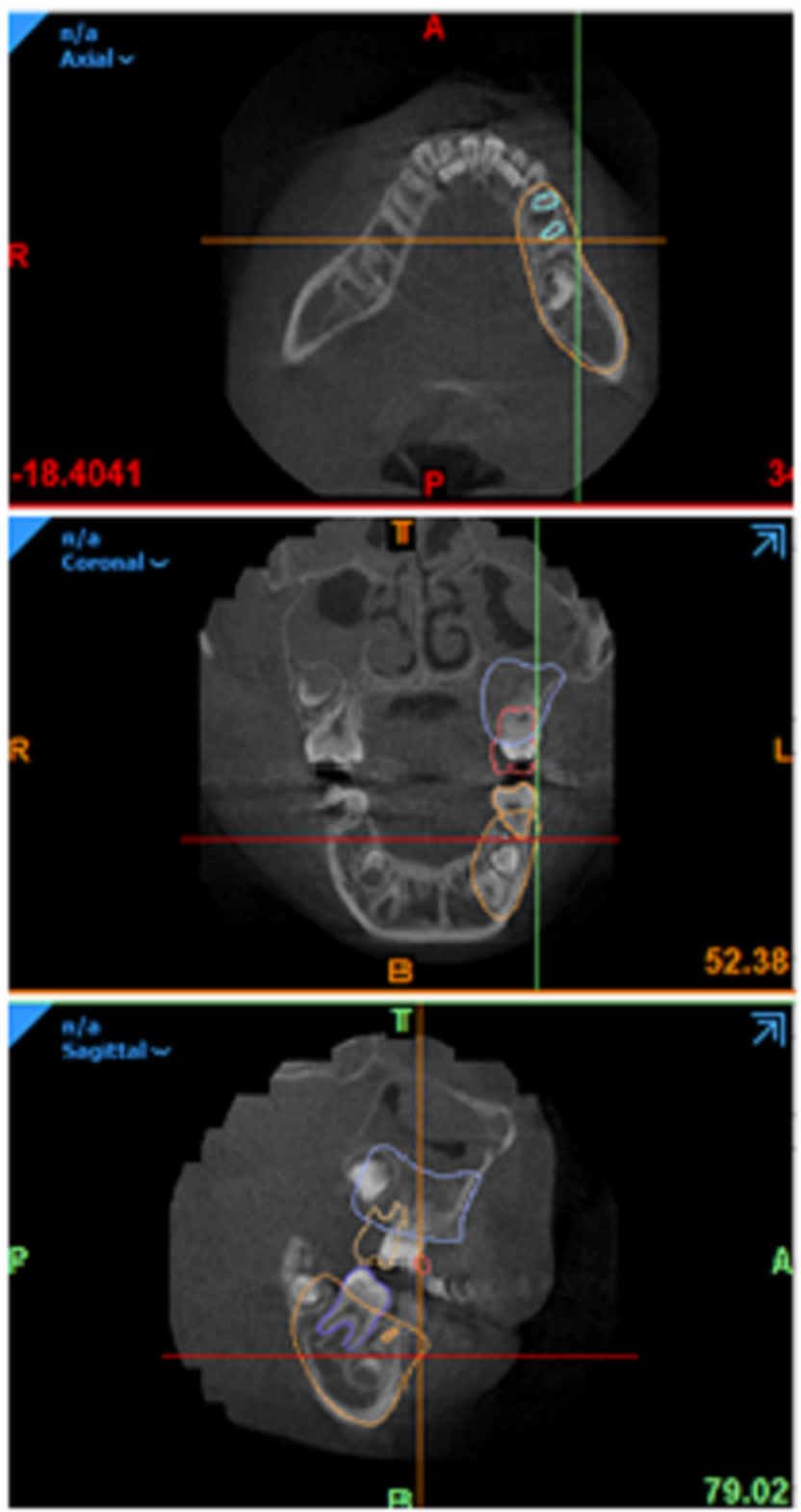

Fig. 1. Cone-beam computed tomography (CBCT) images of a 6-year-old child's dentition

\section{Preparation of a 3D model of the periodontal ligament}

After constructing a 3D model of the teeth, a 3D model of PDL was constructed with a thickness of $0.25 \mathrm{~mm},{ }^{14,15}$ along the anatomic roots (Fig. 2). The periodontal ligament was considered as a uniform mass with linear behavior. Although such a structure does not conform with the real biologic behavior of PDL, various studies have shown that this assumption, i.e., a uniform linear structure, is very valuable for assessing orthodontic forces and appears to be sufficient to explain the initial tooth movements.
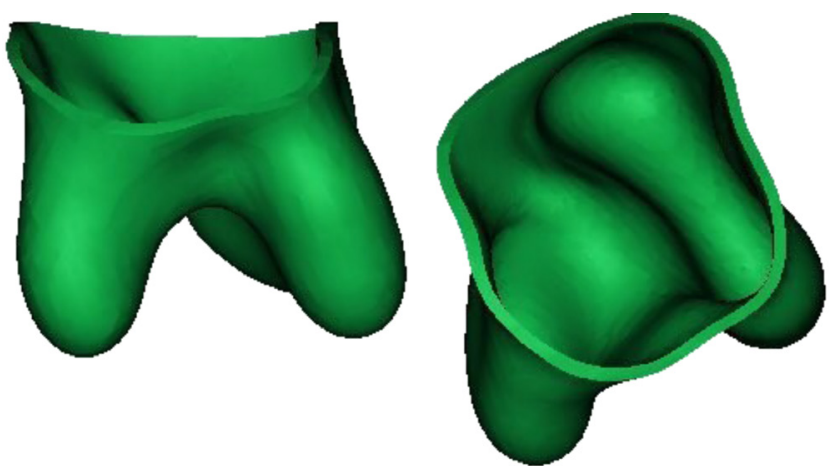

Fig. 2. A three-dimensional (3D) model of the periodontal ligament (PDL) with a thickness of $0.25 \mathrm{~mm}$

\section{Preparation of the bone surrounding the tooth}

The geometry of the maxilla and the mandible was constructed using the CBCT images of a 6-year-old child, and materials were assigned to the spongy- and compact-bone compartments. To design and construct the bone, it was considered as a solid and rigid body. Then, the tooth root-PDL complex was eliminated from this volume by using a complex process with the 'subtract' command (Fig. 3).

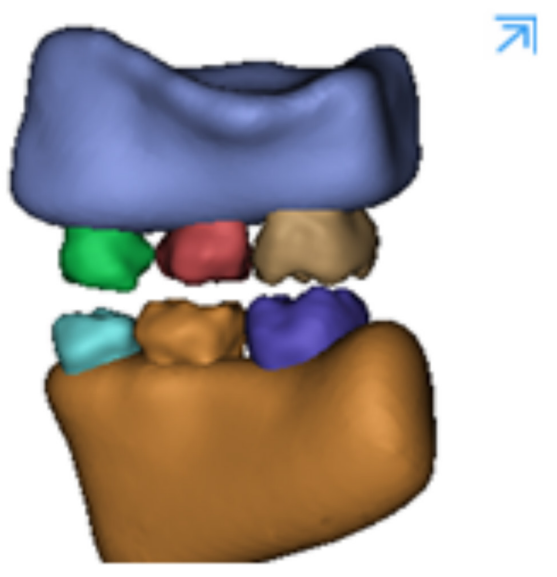

Fig. 3. Geometric model of the maxillary and mandibular bone and the teeth 


\section{Incorporation of the model for drawing}

Geometric software was used to divide the teeth, which were in the form of surfaces, into solid segments. The 3D model was extracted in the SAT format, which could be read in the Essence milieu. With the FE package, point cloud data was converted into $3 \mathrm{D}$ volumes, and then all components were converted into the STP format for FEA.

\section{Preparation of a model of a space maintainer}

A band and loop space maintainer was used to this end. The geometry of the space maintainer was designed in the form of a $0.180 \times 0.005$-inch stainless steel band and a 0.36 -inch stainless steel loop (Fig. 4).

To prepare a geometric model for applying boundary conditions, and for meshing and loading, it is necessary to enter the characteristics of the materials forming each component into a computer. Table 1 presents the physical properties of the materials used in the present study. ${ }^{16}$

The contact between the components was considered complete and tie-bonded. The coefficient of friction between the tooth and the space maintainer was assumed to be $0.2 .^{16}$

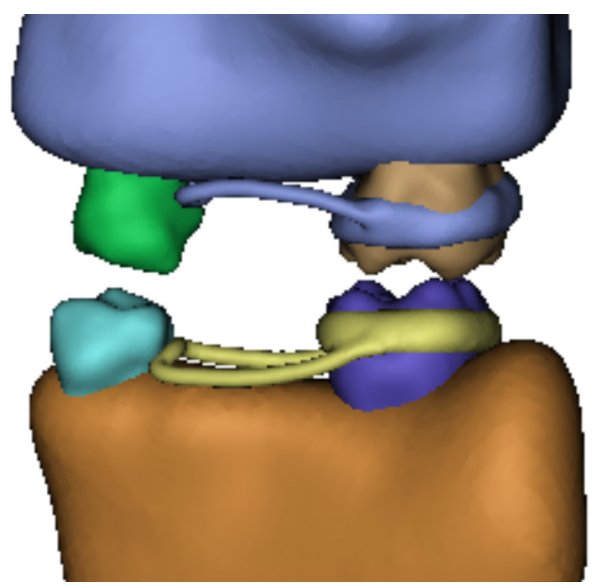

Fig. 4. Geometric model of a band and loop space maintainer
Table 1. Properties of the materials used in the finite element analysis (FEA) model

\begin{tabular}{|l|c|c|c|}
\hline \multicolumn{1}{|c|}{ Component } & Material & $\begin{array}{c}\text { Young's modulus } \\
{[\mathrm{MPa}]}\end{array}$ & $\begin{array}{c}\text { Poisson's } \\
\text { ratio }\end{array}$ \\
\hline Cortical bone & elastic, isotropic & 13,700 & 0.30 \\
Spongy bone & elastic, isotropic & 1,370 & 0.30 \\
PDL & elastic, isotropic & 0.05 & 0.30 \\
Tooth & elastic, isotropic & 20,000 & 0.30 \\
Space maintainer & stainless steel & 193,000 & 0.31 \\
\hline
\end{tabular}

\section{Automatic meshing}

All the components of the 3D model were divided into smaller components (Fig. 5). In addition, the areas subject to the concentration of tensions, such as the apical and alveolar crest areas, were constructed of smaller components to improve the accuracy of these points. The elements were constructed in the form of a tetrahedron. Table 2 presents the approximate number of knots in each component.

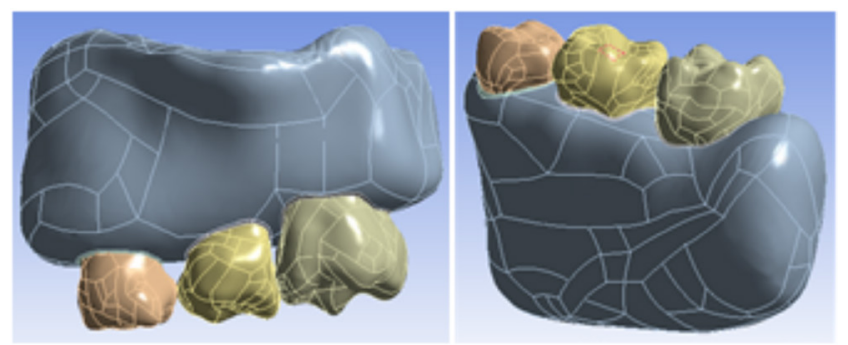

Fig. 5. Automatic meshing of the geometric model

\section{Application of force}

Seventy-newton vertical forces (almost equal to the normal masticatory force) were applied to the mesiopalatal cusp of the maxillary permanent first molar and to the distobuccal cusp of the mandibular permanent first molar (Fig. 6).

Table 2. Component characteristics

\begin{tabular}{|c|c|c|c|}
\hline Component & Element type & Number of nodes & Number of elements \\
\hline Maxillary cortical bone & tetrahedral & 12,002 & 5,240 \\
\hline Maxillary spongy bone & tetrahedral & 10,911 & 6,501 \\
\hline Maxillary first and second primary molars and first permanent molars & tetrahedral & 9,173 & 5,198 \\
\hline PDL of maxillary first and second primary molars and first permanent molars & tetrahedral & 14,482 & 7,085 \\
\hline Maxillary space maintainer & tetrahedral & 6,174 & 2,906 \\
\hline Mandibular cortical bone & tetrahedral & 12,185 & 6,264 \\
\hline Mandibular spongy bone & tetrahedral & 13,457 & 8,218 \\
\hline Mandibular first and second primary molars and first permanent molars & tetrahedral & 8,277 & 4,674 \\
\hline PDL of mandibular first and second primary molars and first permanent molars & tetrahedral & 14,696 & 7,183 \\
\hline Mandibular space maintainer & tetrahedral & 5,693 & 2,705 \\
\hline
\end{tabular}



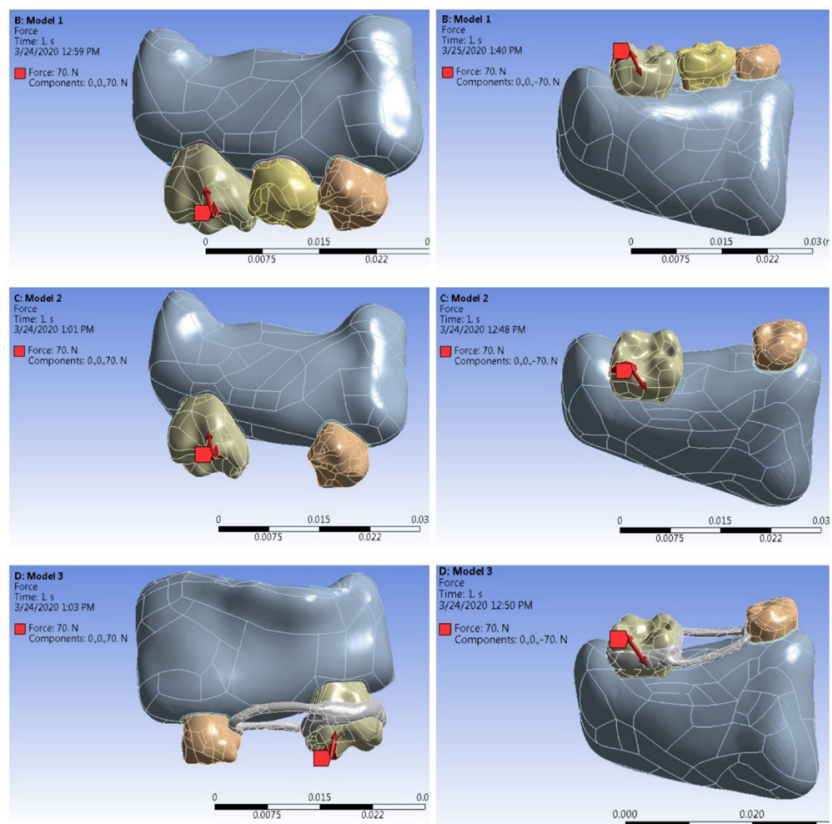

Fig. 6. Load application on the functional cusps of mandibular and maxillary permanent first molars

The different states of the model components were as follows:

1 - the maximum equivalent stress induced and the amount of displacement of the maxillary first molar in an intact arch in the presence of the deciduous second molar;

2 - the maximum equivalent stress induced and the amount of displacement of the maxillary first molar in the absence of the deciduous second molar;

3 - the maximum equivalent stress induced and the amount of displacement of the maxillary first molar in the presence of the space maintainer;

4 - the maximum equivalent stress induced and the amount of displacement of the mandibular first molar in an intact arch in the presence of the deciduous second molar;

5 - the maximum equivalent stress induced and the amount of displacement of the mandibular first molar in the absence of the deciduous second molar;

6 - the maximum equivalent stress induced and the amount of displacement of the mandibular first molar in the presence of the space maintainer.

\section{Results}

A static FEA was carried out in 6 states in the maxilla and the mandible to evaluate the distribution of stresses and the amount of displacement of immature permanent first molar teeth in the presence or absence of deciduous second molar teeth and a space maintainer.

The maximum equivalent stress and displacement of the permanent maxillary first molar are presented in Table 3.

When a $70-\mathrm{N}$ force was applied to the mesiopalatal cusp of the maxillary permanent first molar tooth in the presence of the deciduous second molar tooth, the maximum equivalent stress was recorded at the mesial contact of the crown at $50 \mathrm{MPa}$, and the other parts of the crown and PDL did not exhibit a considerable stress (Fig. 7). The amount of displacement of the permanent first molar was only $0.5 \mu \mathrm{m}$ (Fig. 8 ).

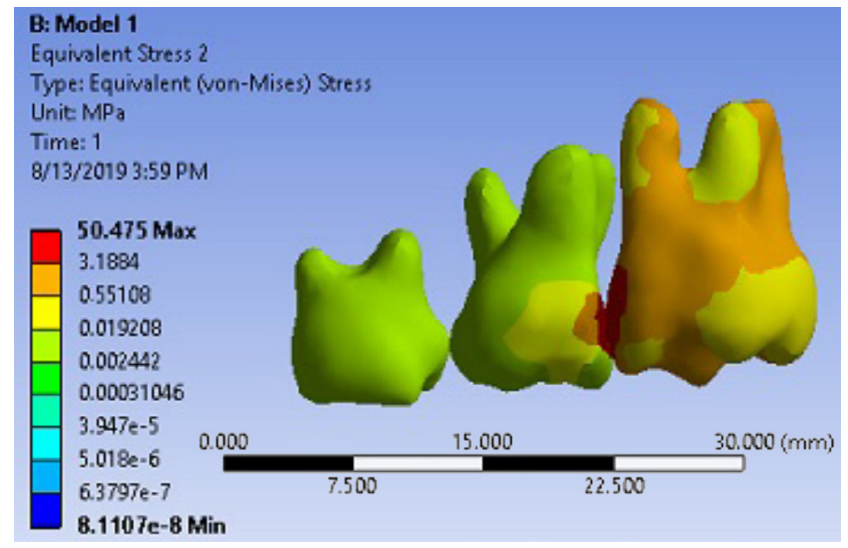

Fig. 7. Pattern of equivalent stress distribution in the maxillary permanent first molar with mesial constraint (distobuccal view)

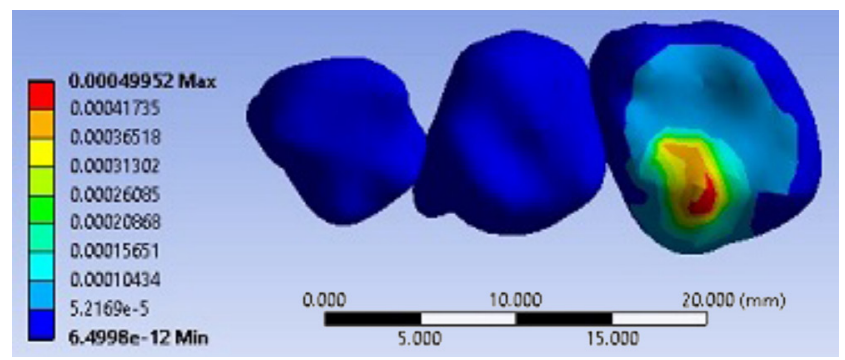

Fig. 8. Displacement pattern in the maxillary permanent first molar with mesial constraint (occlusal view)

Table 3. Maximum equivalent stress and displacement in the crown and roots of the permanent maxillary first molar

\begin{tabular}{|c|c|c|c|}
\hline Particulars & $\begin{array}{c}\text { Presence } \\
\text { of the deciduous second molar }\end{array}$ & $\begin{array}{c}\text { Absence } \\
\text { of the deciduous second molar }\end{array}$ & $\begin{array}{c}\text { Presence } \\
\text { of the space maintainer }\end{array}$ \\
\hline Maximum equivalent stress in the mesiobuccal root [MPa] & 3.15 & 2.45 & 2.58 \\
\hline Maximum equivalent stress in the distobuccal root [MPa] & 0.50 & 2.45 & 0.50 \\
\hline Maximum equivalent stress in the palatal root [MPa] & 3.15 & 12.22 & 2.04 \\
\hline Maximum equivalent stress in the crown [MPa] & $\begin{array}{l}50.00 \\
\text { (the mesial contact of the crown) }\end{array}$ & $\begin{array}{l}2.45 \\
\text { (the mesiopalatal cusp) }\end{array}$ & $\begin{array}{c}10.00 \\
\text { (broad area) }\end{array}$ \\
\hline Maximum displacement [ $\mu \mathrm{m}]$ & 0.5 & 6.5 & 0.6 \\
\hline
\end{tabular}


In the $2^{\text {nd }}$ state, a $70-\mathrm{N}$ force was applied in the absence of the deciduous second molar tooth. In this state, the maximum equivalent stress was recorded in the palatal root of the permanent first molar tooth at $12-16 \mathrm{MPa}$. The crown and the 2 other roots had a low level of stress (Fig. 9). The displacement of the permanent first molar tooth increased in this state and was $6.5 \mu \mathrm{m}$ in the mesiopalatal direction (Fig. 10).

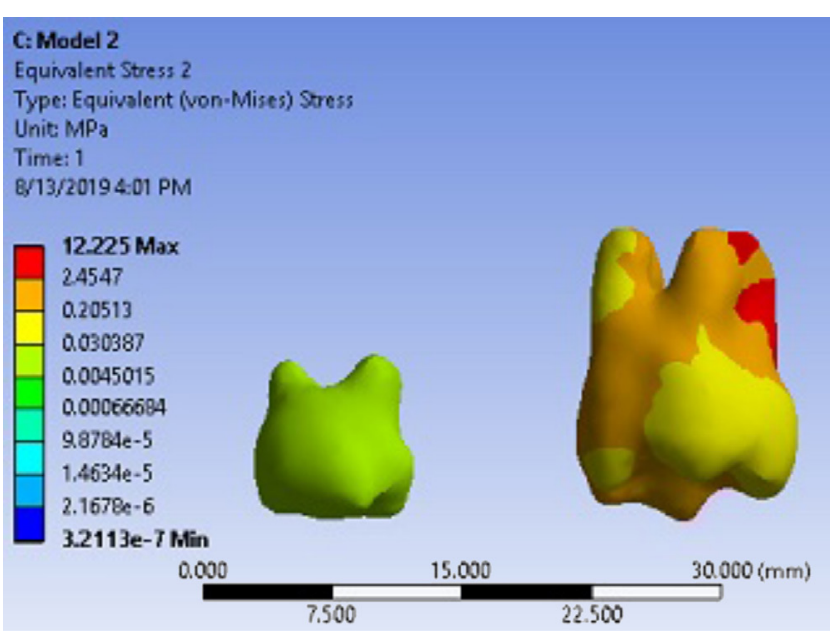

Fig. 9. Pattern of equivalent stress distribution in the maxillary permanent first molar without mesial constraint (distobuccal view)

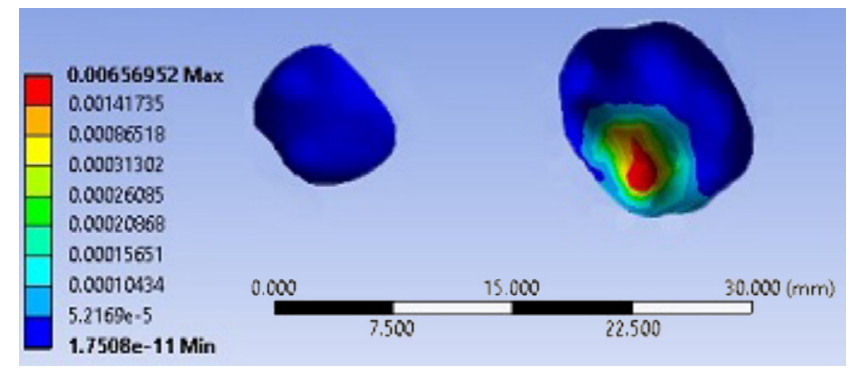

Fig. 10. Displacement pattern in the maxillary permanent first molar without mesial constraint (occlusal view)

In the $3^{\text {rd }}$ state, the force was applied in the presence of the space maintainer. In this state, the maximum equivalent stress on the permanent first molar tooth was recorded on the whole surface of the crown at 10-15 $\mathrm{MPa}$, while the stress in PDL decreased. The maximum equivalent stress in this state was recorded on the surface of the space maintainer and on the distal aspect of the crown of the deciduous first molar tooth (94 MPa) (Fig. 11). A displacement of $0.6 \mu \mathrm{m}$ was recorded in this state (Fig. 12).

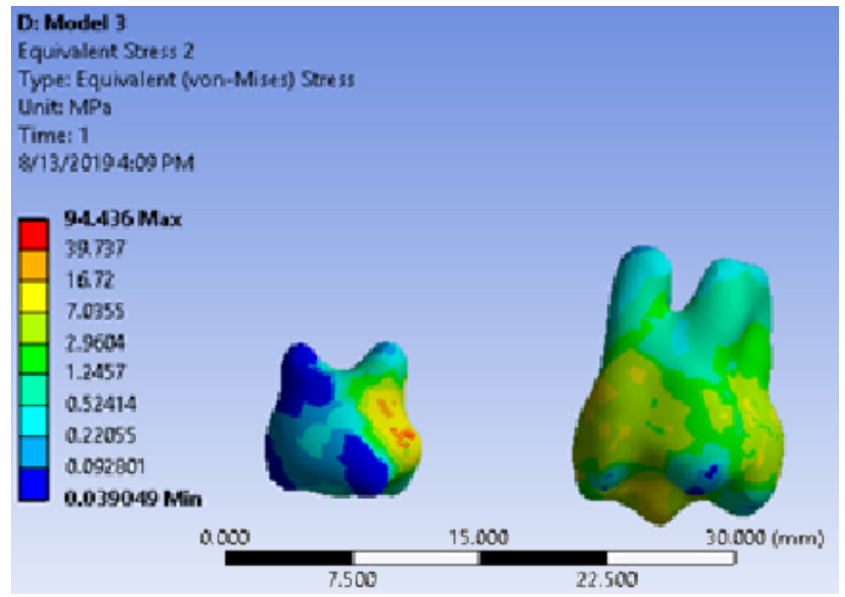

Fig. 11. Pattern of equivalent stress distribution in the maxillary permanent first molar with space maintenance (distobuccal view)

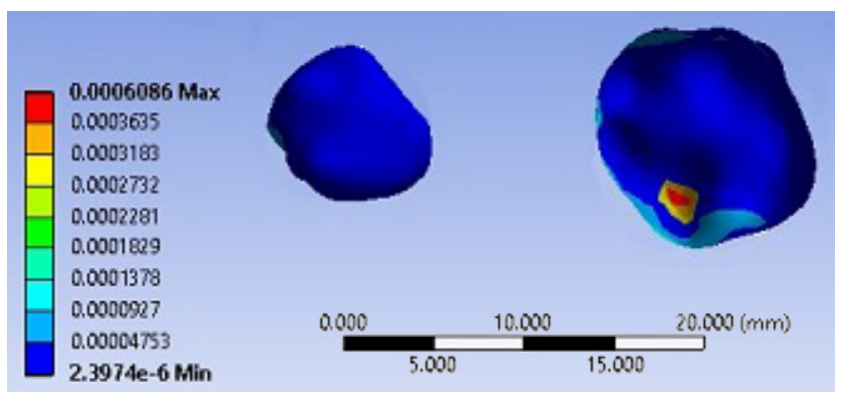

Fig. 12. Displacement pattern in the maxillary permanent first molar with space maintenance (occlusal view)

The maximum equivalent stress and displacement of the permanent mandibular first molar are presented in Table 4.

When a 70-N force was applied to the distobuccal cusp of the mandibular permanent first molar tooth in the $4^{\text {th }}$ state, i.e., in the presence of the deciduous second molar tooth, the maximum equivalent stress was recorded at the mesial contact of the crown at 75.5 MPa. The stress in the roots was similar at 5-6 MPa (Fig. 13). Displacement in this state was $0.8 \mu \mathrm{m}$ (Fig. 14).

The force was applied in the $5^{\text {th }}$ state, i.e., in the absence of the deciduous second molar tooth. In this state, the maximum equivalent stress at the cervical area of the mesial root was $14 \mathrm{MPa}$ (Fig. 15). Displacement in this state was $7.8 \mu \mathrm{m}$ in the mesial direction (Fig. 16).

Table 4. Maximum equivalent stress and displacement in the crown and roots of the permanent mandibular first molar

\begin{tabular}{|c|c|c|c|}
\hline Particulars & $\begin{array}{c}\text { Presence } \\
\text { of the deciduous second molar }\end{array}$ & $\begin{array}{l}\text { Absence } \\
\text { of the deciduous second molar }\end{array}$ & $\begin{array}{c}\text { Presence } \\
\text { of the space maintainer }\end{array}$ \\
\hline Maximum equivalent stress in the mesial root [MPa] & 5.50 & 14.00 & 5.40 \\
\hline Maximum equivalent stress in the distal root [MPa] & 5.50 & 14.00 & 5.40 \\
\hline Maximum equivalent stress in the crown [MPa] & $\begin{array}{l}75.50 \\
\text { (the mesial contact of the crown) }\end{array}$ & $\begin{array}{c}6.35 \\
\text { (the distobuccal cusp) }\end{array}$ & $\begin{array}{c}12.00 \\
\text { (broad area) }\end{array}$ \\
\hline Maximum displacement [ $\mu \mathrm{m}]$ & 0.8 & 7.8 & 0.7 \\
\hline
\end{tabular}




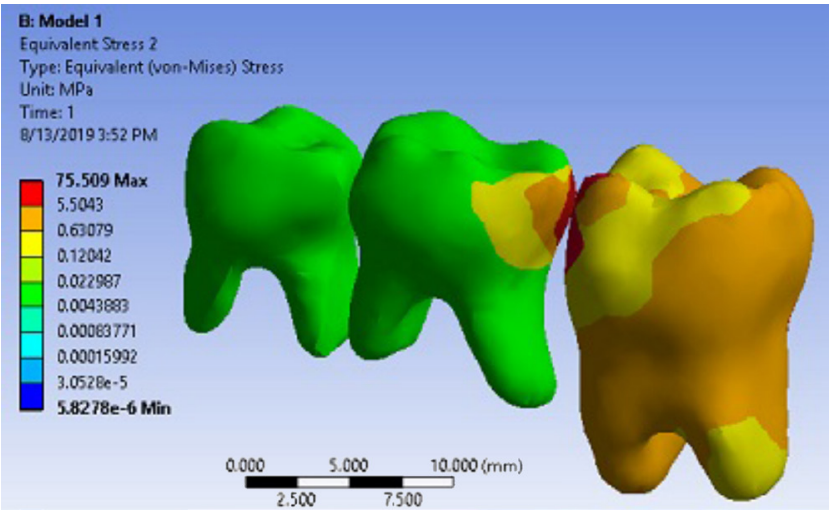

Fig. 13. Pattern of equivalent stress distribution in the mandibular permanent first molar with mesial constraint (distobuccal view)

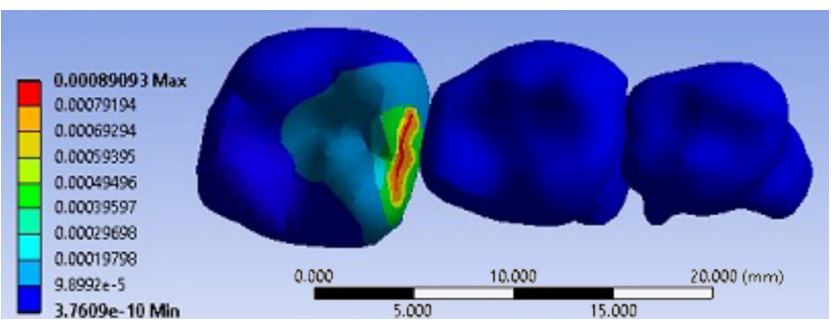

Fig. 14. Displacement pattern in the mandibular permanent first molar with mesial constraint (occlusal view)

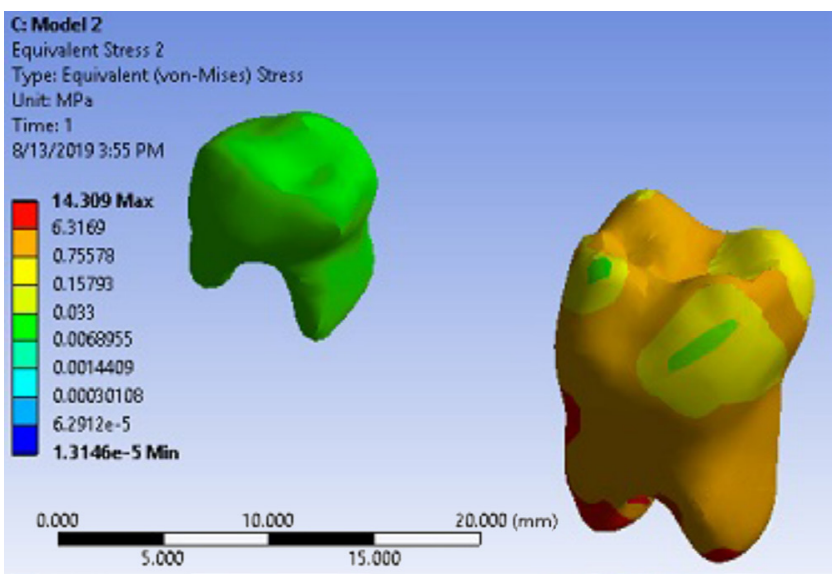

Fig. 15. Pattern of equivalent stress distribution in the mandibular permanent first molar without mesial constraint (distobuccal view)

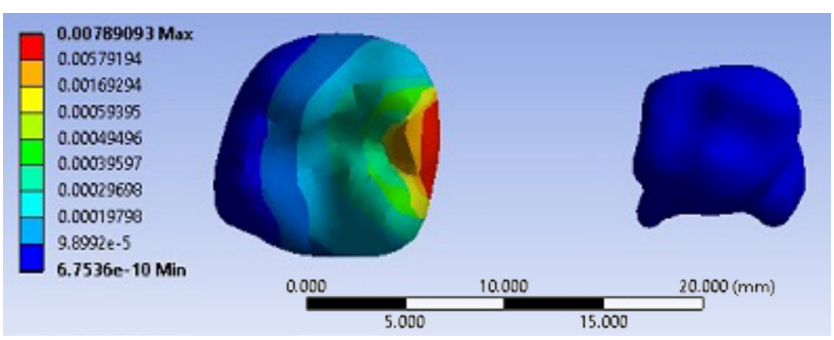

Fig. 16. Displacement pattern in the mandibular permanent first molar without mesial constraint (occlusal view)

In the $6^{\text {th }}$ state, in which the force was applied in the presence of the space maintainer, the maximum equivalent stress on the entire crown surface was $10-12 \mathrm{MPa}$, while the root stress decreased to 5-6 MPa. In the mandible, too, a high rate of stress was applied to the space maintainer and the distal area of the crown of the deciduous first molar tooth (98 MPa) (Fig. 17). Displacement in this state was $0.7 \mu \mathrm{m}$ (Fig. 18).

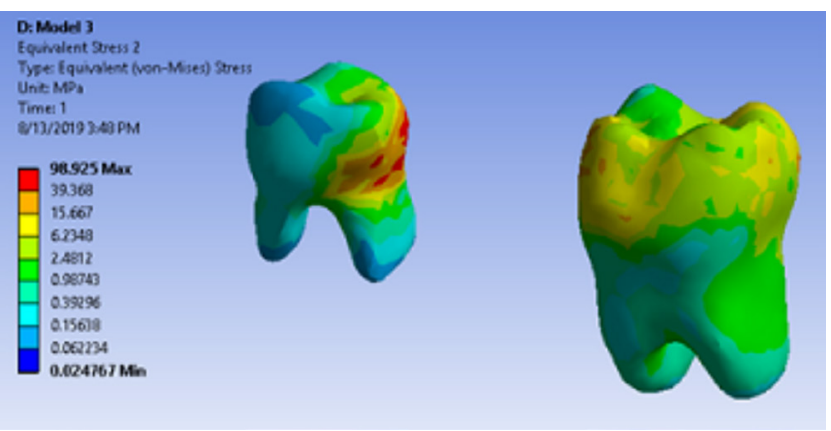

Fig. 17. Pattern of equivalent stress distribution in the mandibular permanent first molar with space maintenance (distobuccal view)

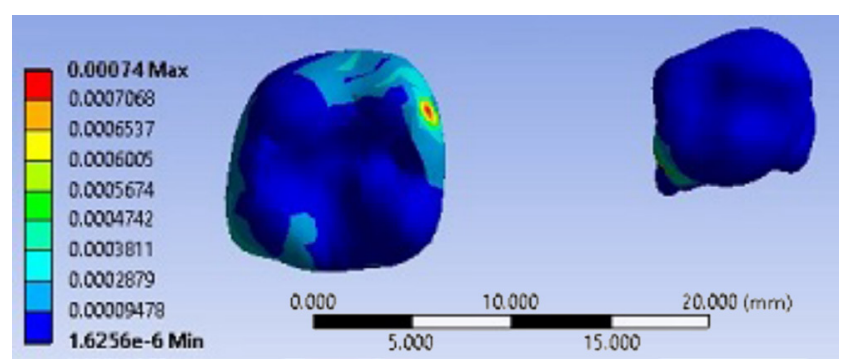

Fig. 18. Displacement pattern in the mandibular permanent first molar with space maintenance (occlusal view)

\section{Discussion}

In FEA, maxillary and mandibular permanent first molars were used to construct a model and simulate changes in the equivalent stress distribution pattern and displacement in the presence and absence of deciduous second molar teeth and a space maintainer.

This analysis is independent of time and shows changes on the spot. However, it is possible to determine changes in the shape of the models in terms of a time factor with the use of some frameworks. This analysis has some obvious advantages, including the fact that it can provide data consistent with real and clinical conditions, and confirm or refute it. Furthermore, it can measure some variables that cannot be observed and measured in real and clinical conditions. ${ }^{17}$

The normal masticatory force is significantly lower than the maximum bite force. The maximum bite force is defined as the maximum force that an individual can apply with their teeth, and is different from the normal masticatory force. In a normal child, this masticatory force is approx. $78 \mathrm{~N} .{ }^{18}$ In the present study, this force for a 6-year-old child was considered at $70 \mathrm{~N}$. 
In an intact dental arch with all the teeth present in both jaws, the maximum equivalent stress was detected at the mesial contact of the permanent first molar tooth, which was transferred to the tooth mesial to the first molar, rather than to its roots. The tooth root, PDL and all the other areas of the tooth crown exhibited much lower stresses, which is consistent with the results of a study by Southard et al., who reported that the anterior component of the occlusal force (ACF) was transferred to the mesial teeth by a proximal contact and could even pass the midline. ${ }^{19}$ Chauhan et al. also reported similar results. ${ }^{12}$

The application of force resulted in the minor displacement of the roots of permanent first molars, and the tooth crown also exhibited a displacement of $0.5-1 \mu \mathrm{m}$, which is not clinically important and can be considered the physiologic displacement of the tooth during mastication. This finding is consistent with the results of clinical studies which showed that in the presence of all teeth, no significant displacement could take place. ${ }^{20}$

In the $2^{\text {nd }} / 5^{\text {th }}$ state, in which deciduous second molars were not present in the dental arch, the maximum equivalent stresses in both arches were transferred to the roots, with higher stresses in the palatal root of the maxillary tooth, followed by the mesiobuccal root. In the mandible, the mesial aspect of the mesial root exhibited the maximum equivalent stress, followed by the mesial aspect of the distal root. These stresses were maximum in the cervical area and the apical area of the roots, which is consistent with the results of a study by Dejak et al., who reported that the maximum stresses during mastication were produced in the occlusal area and in the cervical area of the lingual aspect of permanent first molars in the mandible. ${ }^{21}$ In addition, Petcu et al. carried out a study on subjects during the mixed dentition period and reported that the maximum stress was detected in the cementoenamel junction (CEJ) area and in the coronal third of the root. ${ }^{17}$ Such a discrepancy between the results of studies might be attributed to differences in the anatomy of the teeth and the different developmental stages of immature permanent first molar teeth.

In this state, the maximum equivalent stresses were recorded in the mandibular permanent first molar as compared to the maxilla.

When a permanent first molar tooth is not in contact with a deciduous second molar tooth, the momentary tooth displacement increases 4-5-fold, which is mostly visible in the crown area, while the roots are displaced at a lower rate. Therefore, both maxillary and mandibular permanent first molars tend to tip mesially, rather than move bodily, which was confirmed in the present study and reported in previous clinical studies. ${ }^{22}$ In studies by Chauhan et al. ${ }^{12}$ and Kojima and Fukui, ${ }^{23}$ the FEA of maxillary permanent first molar teeth showed that the mesial tipping of these teeth was greater than their bodily movement. In the present study, such displacement of maxillary first molars was observed in the mesiopalatal direction, with only mesial displacement in the case of mandibular first molars.
The comparison of displacement between the 2 jaws showed that the displacement of the lower first molar was greater than that of the upper first molar, which does not coincide with the results of previous clinical studies., It can be concluded that, although momentary displacement in the mandible is greater than in the maxilla, more displacement will occur in the maxilla over time due to the more spongy nature of the maxillary bone.

The amount of displacement of the roots was much smaller than that of the tooth crown, and the displacement of the roots of the mandibular first molar was lesser than in the case of the maxillary first molar, indicating much fewer bodily movements in the mandible as compared to the maxilla. Chauhan et al. also recorded some bodily movement in maxillary first molar teeth. ${ }^{12}$

When the force was applied in the presence of the space maintainer, stresses on the crown and the roots decreased significantly, and were transferred to the space maintainer itself. In addition, high stresses were recorded in the distal aspect of the crowns of deciduous first molars. In the present study, stresses in the distal aspect of the deciduous mandibular first molar were higher than those in the distal aspect of the corresponding tooth in the maxilla. Such a difference might be explained by differences in the anatomy of the teeth between the 2 jaws.

The amount of tooth displacement that was recorded in this state decreased almost to that from the $1^{\text {st }} / 4^{\text {th }}$ state in an intact arch, and tooth tipping, which was observed in the absence of second primary molars and without mesial constraint, decreased significantly. However, a small amount of root displacement is not clinically important. ${ }^{24}$

The results of the present study showed that when a permanent first molar tooth erupts, if a deciduous second molar tooth is not in contact with the mesial aspect of the erupting tooth, a large amount of the arch length will be lost and the space will be closed over time. No study to date has evaluated the equivalent stresses exerted on the tooth, the space maintainer and the distal aspect of the deciduous second molar tooth. The results of the present study showed the pattern of distribution of the equivalent stress during mastication; the results also showed that space maintainers are useful in preventing the momentary displacement of the teeth.

\section{Conclusions}

The results showed the importance of the use of space maintainers, as they significantly decrease the momentary displacement of the teeth as well as the stress exerted on the developing permanent first molar teeth.

\section{ORCID iDs}

Arghavan Kamali Sabeti (D) https://orcid.org/0000-0003-4862-1116 Zahra Karimizadeh (D) https://orcid.org/0000-0002-2960-9210 Rezvan Rafatjou (D) https://orcid.org/0000-0002-3333-1725 


\section{References}

1. Pokorná H, Marek I, Kucera J, Hanzelka T. Space reduction after premature loss of a deciduous second molar - retrospective study. IOSR J Dent Med Sci. 2016;15(11):1-8. doi:10.9790/0853-1511020108

2. Smith SL, Buschang PH. Growth in root length of the mandibular canine and premolars in a mixed-longitudinal orthodontic sample. Am J Hum Biol. 2009;21(5):623-634. doi:10.1002/ajhb.20873

3. Ciftci V, Uzel A, Dogan MC. Evaluation of skeletal and dental effects of lower lingual arches. J Clin Pediatr Dent. 2018;42(6):469-474. doi:10.17796/1053-4625-42.6.13

4. Ahmad A, Parekh S, Ashley PF. Methods of space maintenance for premature loss of a primary molar: A review. Eur Arch Paediatr Dent. 2018;19(5):311-320. doi:10.1007/s40368-018-0357-5

5. Bindayel NA. Clinical evaluation of short term space variation following premature loss of primary second molar, at early permanent dentition stage. Saudi Dent J. 2019;31(3):311-315. doi:10.1016/j.sdentj.2019.03.002

6. Srivastava N, Grover J, Panthri P. Space maintenance with an innovative "Tube and Loop" space maintainer (Nikhil appliance). Int J Clin Pediatr Dent. 2016;9(1):86-89. doi:10.5005/jp-journals-10005-1340

7. Gray S, Stacknik S, Farella M. Space maintenance: An overview for clinicians. N Z Dent J. 2016;112(3):76-80.

8. Chandra HS, Krishnamoorthy SH, Johnson JS, Prabhu S. III effects of conventional band and loop space maintainers: Time to revolutionise. Int Dent Med J Adv Res. 2018;4:1-3. doi:10.15713/ins.idmjar.83

9. Rajah LD. Clinical performance and survival of space maintainers: Evaluation over a period of 5 years. ASDC J Dent Child. 2002;69(2):156-160. PMID:12515058

10. Zhang YR, Du W, Zhou XD, Yu HY. Review of research on the mechanical properties of the human tooth. Int J Oral Sci. 2014;6(2):61-69. doi:10.1038/ijos.2014.21

11. Parcha E, Bitsanis E, Halazonetis DJ. Morphometric covariation between palatal shape and skeletal pattern in children and adolescents: A cross-sectional study. Eur J Orthod. 2017;39(4):377-385. doi:10.1093/ejo/cjw063

12. Chauhan SP, Sharma DS, Jain M. Initial stresses induced in permanent maxillary first molar in mixed dentition under normal masticatory forces: A finite element study. J Clin Pediatr Dent 2016;40(4):334-340. doi:10.17796/1053-4628-40.4.334

13. Zhang $\mathrm{H}$, Cui JW, Lu XL, Wang MQ. Finite element analysis on tooth and periodontal stress under simulated occlusal loads. J Oral Rehabil. 2017;44(7):526-536. doi:10.1111/joor.12512
14. Heravi F, Salari S, Tanbakuchi B, Loh S, Amiri M. Effects of crownroot angle on stress distribution in the maxillary central incisors' PDL during application of intrusive and retraction forces: A threedimensional finite element analysis. Prog Orthod. 2013;14:26. doi:10.1186/2196-1042-14-26

15. Hedayati $Z$, Shomali M. Maxillary anterior en masse retraction using different antero-posterior position of mini screw: A 3D finite element study. Prog Orthod. 2016;17(1):31. doi:10.1186/s40510-016-0143-z

16. Tominaga J, Ozaki $\mathrm{H}$, Chiang PC, et al. Effect of bracket slot and archwire dimensions on anterior tooth movement during space closure in sliding mechanics: A 3-dimensional finite element study. Am J Orthod Dentofacial Orthop. 2014;146(2):166-174. doi:10.1016/j.ajodo.2014.04.016

17. Petcu A, Bălan A, Haba D, Dumitraş C. Importance of the mathematical model in the premature loss of the lower temporary molar. Pediatr Dent. 2014;18(4):296-300.

18. Castelo PM, Duarte Gavião MB, Pereira LJ, Bonjardim LR. Masticatory muscle thickness, bite force, and occlusal contacts in young children with unilateral posterior crossbite. Eur J Orthod. 2007;29(2):149-156. doi:10.1093/ejo/cjl089

19. Southard TE, Behrents RG, Tolley EA. The anterior component of occlusal force. Part 1. Measurement and distribution. Am JOrthod Dentofacial Orthop. 1989;96(6):493-500. doi:10.1016/0889-5406(89)90116-9

20. Natali AN, Pavan PG, Scarpa C. Numerical analysis of tooth mobility: Formulation of a non-linear constitutive law for the periodontal ligament. Dent Mater. 2004;20(7):623-629. doi:10.1016/j.dental.2003.08.003

21. Dejak B, Młotkowski A, Romanowicz M. Finite element analysis of stresses in molars during clenching and mastication. J Prosthet Dent. 2003;90(6):591-597. doi:10.1016/j.prosdent.2003.08.009

22. Lin YT, Lin WH, Lin YTJ. Immediate and six-month space changes after premature loss of a primary maxillary first molar. J Am Dent Assoc. 2007;138(3):362-368. doi:10.14219/jada.archive.2007.0169

23. Kojima $Y$, Fukui H. Effects of transpalatal arch on molar movement produced by mesial force: A finite element simulation. Am J Orthod Dentofacial Orthop. 2008;134(3):335.e1-e7;discussion 335-336. doi:10.1016/j.ajodo.2008.03.011

24. Mühlemann HR. Tooth mobility: A review of clinical aspects and research findings. J Periodontol. 1967;38(6)Suppl:686-713. doi:10.1902/jop.1967.38.6_part2.686 